\title{
Pricing Damaged Goods
}

\author{
R. Preston McAfee \\ California Institute of Technology
}

\begin{abstract}
:
Companies with market power occasionally engage in intentional quality reduction of a portion of their output as a means of offering two qualities of goods for the purpose of price discrimination, even absent a cost saving. This paper provides an exact characterization in terms of marginal revenues of when such a strategy is profitable, which, remarkably, does not depend on the distribution of customer valuations, but only on the value of the damaged product relative to the undamaged product. In particular, when the damaged product provides a constant proportion of the value of the full product, selling a damaged good is unprofitable. One quality reduction produces higher profits than another if the former has higher marginal revenue than the latter.
\end{abstract}

JEL: $\quad$ D43, L15

Correspondence: preston@mcafee.cc or 100 Baxter Hall, Caltech 228-77, Pasadena, CA 
Electronics company Sharp sells many DVD players, including two with model numbers DVE611 and DV740U (now discontinued). A major difference between these units, perhaps the major difference, is the former's ability to play PAL DVD discs. PAL is the European television standard with 576 lines on the screen, while North America uses NTSC, with 480 lines. (Both have 720 columns.) The DV740U device lacks the ability to play PAL discs and still output to an NTSC television - or does it? In fact, the DC740U has the ability to play PAL discs, but this facility is suppressed by using a different plastic cover on the remote, a cover which hides a critical button. Enthusiasts have discovered a simple means to turn the less expensive unit into a full-featured unit, simply by cutting a hole in the plastic cover, which is illustrated in Figure 1.

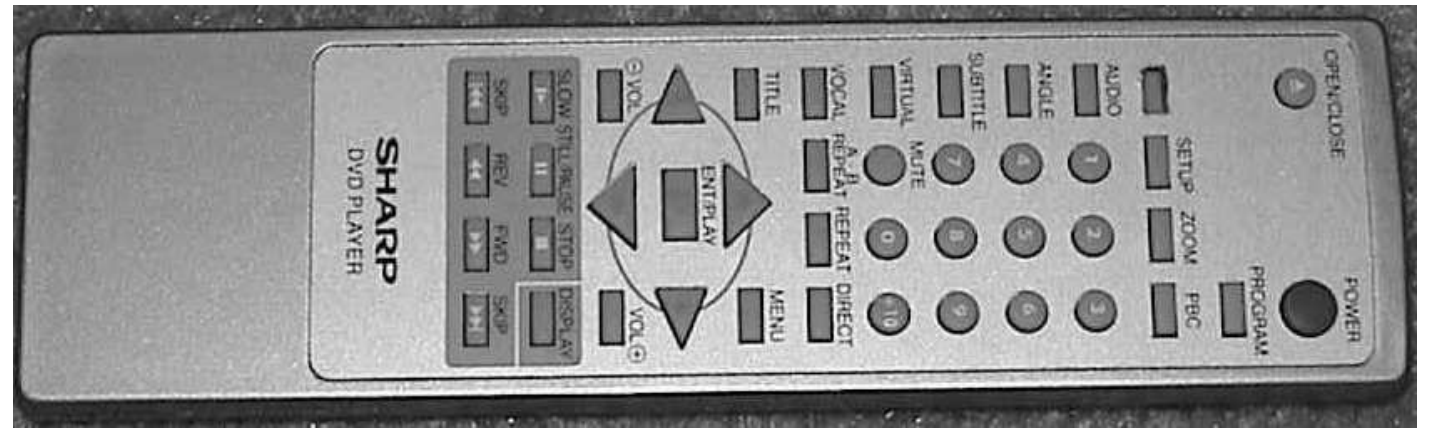

Figure 1: Hacked Remote Control of the DV740U (Courtesy of Area 450). Note the extra button in upper right portion of image.

Sharp Electronics has directly damaged the product by hiding the control. This solution permits Sharp to exploit economies of scale on the manufacture of DVD players, while still offering two quite different sets of features, one clearly better than the other. Is this a profitable strategy for Sharp?

A crimped or light version of a product represents an intentional reduction in value of the product, which is known in the literature as a damaged good (Deneckere and McAfee, (1996)). Crimping refers to manufacturers who sell two versions of a product, which differ only because some features have been disabled in one of them, in 
order to price discriminate. For example, Vegas Movie Studio+DVD offers a regular version, at a suggested retail price of $\$ 129.99$, and a Platinum version, which offers additional features, for $\$ 179.99$. While the additional features of the Platinum edition may have cost more to create in the first place, the marginal cost is the same - a CD and manual, and given some scale economies in maintenance, manufacture and support, offering two versions may be more expensive than offering the Platinum version alone. The basic and premium version represents a common price discrimination strategy in software.

This paper investigates when offering a crimped version is profit-maximizing, when there is no cost saving or penalty associated with crimping. The absence of a cost associated with crimping is important because it insures that a competitive market would only offer the high quality good, and thus that offering the low quality good at a discount is definitely price discrimination. A simple formula establishes when offering a crimped version of their product is profitable. This formula predicts which products will be sold in two versions and how to the versions will be priced. Profitability does not depend on the distribution of valuations, only the relative valuations. The characterization of quantities sold is cast in terms of the familiar notion of marginal revenue. Reflected in terms of the type of customer, the low quality good is sold to the customer whose marginal revenue exceeds marginal cost (the usual monopoly result), while the high quality good is sold to the customer whose marginal revenue exceeds the marginal revenue of the low quality good. The implication of this characterization is that, when both goods are sold, the monopoly quantity for the low quality good are purchased, while the quantity of the high quality good doesn't depend on marginal cost, although marginal cost can influence whether the low quality good is offered at all. 
Finally, the marginal revenue construct permits a characterization of when one crimp is more profitable than another.

Deneckere and McAfee (1996) present several striking examples of damaged goods. An economically important example they do not discuss is the common Saturday night stay-over restriction in air travel, which is used to justify a discount fare. Since a Saturday night stay-over requirement doesn't restrict the days on which the customer flies, the requirement is not akin to the matinee showing at a movie theater, which has a low price because the matinee is an off-peak time. The Saturday night stay-over in fact permits travel at peak times. The restriction works as a price discrimination tool because the passengers with the highest value are often traveling for work, and would like to be home for the weekend, a goal prohibited by the requirement to span a Saturday night.

Speedy mail service Federal Express offers several levels of service, including next day air and second day air. Several consultants have told me that Fedex holds second day packages back, in order to insure that second day air isn't chosen by individuals who would be satisfied with a high probability of next day delivery. To test this claim, I mailed packages on March 22, 2006 from Pasadena, CA, to four destinations, simultaneously mailing next day and second day air packages. The results are presented in Table 1.

Table 1: Fedex Next Day and Second Day Delivery Times

\begin{tabular}{|l|r|r|r|}
\hline \multicolumn{1}{|c|}{ Destination } & \multicolumn{1}{|c|}{$\begin{array}{c}\text { Distance } \\
\text { (mi) }\end{array}$} & $\begin{array}{c}\text { Next Day } \\
\text { (Hours) }\end{array}$ & $\begin{array}{c}\text { Second Day } \\
\text { (Hours) }\end{array}$ \\
\hline San Marino, CA & 2 & $19^{1 / 2}$ & 20 \\
\hline Stanford, CA & 359 & 20 & $43^{1 / 2}$ \\
\hline Jacksonville, FL & 2418 & 17 & 42 \\
\hline Richmond, VA & 2634 & 17 & 41 \\
\hline
\end{tabular}


The results are mixed. The nearby second day package was delivered a day early, while the three other packages were held back. According to the website records, these three were held in the Los Angeles facility for a day, and then shipped in one day, as opposed to shipping by some slower means. Thus, Fedex is not systematically holding back all second day packages, but may engage in some reduction of the quality of the second day product.

Mussa and Rosen (1978) were the first to formally consider a seller who can offer multiple qualities. Mussa and Rosen assume that the value of the crimped product is a constant proportion of the value of the high quality product. Besanko, Donnenfeld and White (1988) and Kim (1987) and most of the literature make a similar assumption. As we will show, with proportional valuations a crimped good is never offered if the cost is the same. Ellison and Fudenberg (2000) consider the incentive of a seller to offer too many software upgrades, essentially using a network externality to induce others who don't need the increased functionality of the upgrade to buy it anyway. Their solution offers an alternative reason for crimped products, with today's full featured product being tomorrow's crimped product. Armstrong (1996) characterizes the solution of a much more general multi-dimensional problem. Srinagesh and Bradburd (1989) offer a very general analysis for the case where there are two types of customer. Deneckere and McAfee (1996) show, in the same model analyzed here, that offering a second version can be a Pareto improvement - the seller and all types of buyers can be better off with the introduction of a crimped product. That paper does not characterize the profitability of offering a crimped product in general, but does provide a sufficient condition that depends on the distributions of valuations. Anderson and Dana (2005), independently from this paper, characterize the profitability of price discrimination in a 
much larger class of environments and prove a substantially more general version of the first two results of this paper. Anderson and Dana's result is that log-supermodularity of the value function is sufficient for price discrimination to be profitable, while logsubmodularity is sufficient for it not to be profitable; log-supermodularity corresponds to increasing percentage differences in the model provided here. In contrast to this paper, Anderson and Dana do not provide the marginal revenue characterization and do consider optimal crimping. Hahn (2006) also proves a version of the optimal crimping result. (See Jing (2007) for an analysis in the context of networks.) Finally, delightful papers by Johnson and Myatt (2003, 2006) demonstrate local necessity and global sufficiency of supermodularity as well as a plethora of other results, but do not cast the results in terms of marginal revenue nor prove the optimal crimping result.

\section{The Incentive to Offer a Crimped Product}

To establish when crimping the product is profitable, we consider a seller with market power who offers two distinct qualities of the good, a low quality or light version, and a high quality version, both with the same marginal cost $c$. There are two values for each customer - the value of the high quality product and the value of the low quality product. Generally this leads to a two dimensional description of customer preferences, but the theory developed here follows Deneckere and McAfee (1996) and assumes that the value of the low quality, or crimped, product is a monotonic function of the value of the high quality product. For a customer with value $v$ of the high quality product, let $\lambda(v)$ represent the value of the crimped product. Let $F$ be the cumulative distribution function, with density $f$, of the value of the full quality product. The following assumptions seem natural and are maintained throughout the analysis:

(1) $\lambda(0)=0$, 
(2) $\quad 0 \leq \lambda^{\prime}(v)<1$.

Hypothesis (1) insures that a customer placing zero value on the good also doesn't value the crimped version, and that a customer with a higher value than a second customer is willing to pay more for the crimped version, but not too much more. Were $\lambda^{\prime}(v)>1$, the crimped version is in some sense offering more value to the customer, at least at the margin. Let $p_{H}$ be the price of the regular or high-quality good, and $p_{L}$ be the price of the low-quality or crimped version.

A customer chooses to purchase the full version if it offers higher value net of the purchase price than the crimped version, and if the net value is non-negative. The full version offers a higher value if $v-p_{H} \geq \lambda(v)-p_{L}$. Because $v-\lambda(v)$ is a non-decreasing function of $v$, there is a value $x_{H}$ so that the customer prefers $H$ over $L$ if $v \geq x_{H}$, and $x_{H}$ is given by

(3) $x_{H}-\lambda\left(x_{H}\right)=p_{H}-p_{L}$.

A customer is willing to purchase the crimped version if it offers non-negative value, that is, if $\lambda(v)-p_{L} \geq 0$. This is equivalent to $v \geq x_{L}$, where $x_{L}$ satisfies:

(4) $\quad p_{L}=\lambda\left(x_{L}\right) \cdot^{1}$

In order for both versions of the product to be purchased by some types of customers, it is necessary that $x_{L}<x_{H}$.

Lemma 1: $x_{L}<x_{H}$ if and only if $p_{L}<\lambda\left(p_{H}\right)$.

All proofs are contained in the appendix. The lemma proves the intuitive proposition that there is demand for the crimped good if the price is less than the value

\footnotetext{
${ }^{1}$ In the event that (4) has more than one solution, the relevant solution is the infimum.
} 
of the crimped good for a customer who is just indifferent to buying the regular good, and who hence has a value $p_{H}$. Applying (3) and (4), the profits of the seller are

$$
\begin{aligned}
\pi & =\left(1-F\left(x_{H}\right)\right)\left(p_{H}-c\right)+\left(F\left(x_{H}\right)-F\left(x_{L}\right)\right)\left(p_{L}-c\right) \\
& =\left(1-F\left(x_{H}\right)\right)\left(p_{H}-c\right)+\left[\left(1-F\left(x_{L}\right)-\left(1-F\left(x_{H}\right)\right)\right]\left(p_{L}-c\right)\right. \\
& =\left(1-F\left(x_{H}\right)\right)\left(p_{H}-p_{L}\right)+\left(1-F\left(x_{L}\right)\right)\left(p_{L}-c\right) \\
& =\left(1-F\left(x_{H}\right)\right)\left(x_{H}-\lambda\left(x_{H}\right)\right)+\left(1-F\left(x_{L}\right)\right)\left(\lambda\left(x_{L}\right)-c\right) .
\end{aligned}
$$

As constructed, the profit function assumes $x_{L} \leq x_{H}$, because otherwise the term $F\left(x_{H}\right)-F\left(x_{L}\right)$ does not represent the quantity of the crimped good sold. A seller selling only one quality would always sell the high quality, since a higher price can be charged for it. The seller would like to maximize $\pi$ subject to the constraint that $x_{L} \leq x_{H}$. Then the prices are found by solving (3) and (4).

It is useful to assume decreasing marginal revenue on both the regular good and the crimped good and we will do so here. If a price $p$ is charged for the regular good, since the quantity of sales is $(1-F(p))$, the marginal revenue is

$$
M R_{H}=\frac{\frac{d}{d p} p q}{\frac{d q}{d p}}=\frac{\frac{d}{d p} p(1-F(p))}{\frac{d}{d p}(1-F(p))}=\frac{-p f(p)+(1-F(p))}{-f(p)}=p-\frac{(1-F(p))}{f(p)} .
$$

Noting that $\mathrm{MR}_{\mathrm{H}}$ is decreasing in quantity if it is increasing in price, we have that decreasing marginal revenue is equivalent to the familiar assumption that

(7) $p-\frac{1-F(p)}{f(p)}$ is an increasing function.

The quantity sold of the crimped good, given a price $p$, is $1-F\left(\lambda^{-1}(p)\right)$, so the marginal revenue for the crimped good is 


$$
\begin{aligned}
M R_{L} & =\frac{\frac{d}{d p} p q}{\frac{d q}{d p}}=\frac{\frac{d}{d p} p\left(1-F\left(\lambda^{-1}(p)\right)\right)}{\frac{d}{d p}\left(1-F\left(\lambda^{-1}(p)\right)\right)}=\frac{-p f\left(\lambda^{-1}(p)\right) \lambda^{-1}(p)+(1-F(p))}{-f\left(\lambda^{-1}(p)\right) \lambda^{-1}(p)} \\
& =p-\frac{\left(1-F\left(\lambda^{-1}(p)\right)\right)}{f\left(\lambda^{-1}(p)\right)} \lambda^{\prime}\left(\lambda^{-1}(p)\right) .
\end{aligned}
$$

Thus, since $\lambda$ is non-decreasing, the marginal revenue is decreasing if and only if

(9) $\lambda(p)-\frac{1-F(p)}{f(p)} \lambda^{\prime}(p)$ is increasing.

Theorem 1: Suppose $\lambda(x)-c \leq \lambda^{\prime}(x)(x-c)$ for all $x \geq \lambda^{-1}(c)$. Then only one good is sold by a monopolist.

The hypothesis of Theorem 1 is equivalent to

(10) $\frac{\lambda(x)-c}{x-c}$ increasing in $x$ for $x \geq \lambda^{-1}(c)$.

This formula has the simple interpretation that if high value customers have a relatively high value of the crimped product, where value is measured net of the cost of the product, then it is unprofitable to offer the crimped product, as the losses on high value customers exceed the gains from selling to low value customers.

Theorem 1 subsumes two interesting cases.

Case 1: (Proportional crimped value) If $\lambda(x)=\beta x$, for $0 \leq \beta<1$, then $\lambda(x)-c \leq \lambda^{\prime}(x)(x-c)$ and it never pays to offer the crimped good.

Case 2: (Convex crimped value) If $\lambda$ is convex, then $\lambda(x) \leq x \lambda^{\prime}(x)$, and thus the hypothesis of Theorem 1 is automatically satisfied. Consequently, a monopolist only offers one quality. This case, in particular, covers $\lambda(x)=\operatorname{Max}\{0, x-a\}$, where the 
crimped product removes a constant from the value. ${ }^{2}$ Deneckere and McAfee (1996) show that if $\lambda(x) / x$ is increasing, then offering the damaged good is unprofitable, which is an immediate corollary as well.

Our next result shows that the condition (10) is exact, in the sense that if it fails at the monopoly price, then it is profitable to sell both qualities. Let $p^{H}$ be the monopoly price associated with selling only one quality.

Theorem 2: Suppose $\lambda\left(p^{H}\right)-c>\lambda^{\prime}\left(p^{H}\right)\left(p^{H}-c\right)$. Then it is profitable to sell both qualities.

Theorem (2) shows a form of converse to Theorem 1. If the condition (10) fails at the monopoly price, then it is profit-maximizing for the seller to offer two qualities. If so, the optimal customer types that purchase the goods satisfy:

$$
M R_{L}\left(\lambda\left(x_{L}\right)\right)=c
$$

and

$$
M R_{H}\left(x_{H}\right)=M R_{L}\left(\lambda\left(x_{H}\right)\right)
$$

Equation (11) shows that the lowest-value customer who buys the crimped product is the same as would arise with a monopolist selling only the crimped product. This will be less than the lowest-value customer who buys the regular product from a regular-product-only monopolist, so the total sales rise when it is profitable to sell both types of good. 3 Equation (12) determines the marginal customer type who buys the high value product. The remarkable thing about this equation is that it doesn't depend on the cost of the product; when both qualities are sold, the marginal customer type buying the

\footnotetext{
${ }^{2}$ This case takes special handling because $x_{H}$ is not uniquely defined, but there is no value of $x_{H}$ consistent with customer optimization in which it is profitable for the seller to offer the crimped version.

${ }^{3}$ The assumption that each customer buys at most one unit, relevant in most applications, matters. In the single good context, Varian (1985) shows that the quantity rises as well, a fact that isn't true with more general demand.
} 
high value product is determined by equating the marginal revenues of the high quality and low quality product. The actual price charged for the high quality product does depend on the cost through the price of the low quality product:

$$
p_{H}=x_{H}-\lambda\left(x_{H}\right)+p_{L}=x_{H}-\lambda\left(x_{H}\right)+\lambda\left(x_{L}\right),
$$

because $x_{L}$ depends on $c$ via (11).

\section{Comparing Crimps}

Suppose a company has two distinct crimping technologies available for its product, $\lambda$ and $\mu$, and that both satisfy the hypotheses (1)-(2) and decreasing marginal revenue. Which crimp produces a higher profit?

Theorem 3: Suppose it is profitable to offer a crimped version with either of two technologies $\lambda$ and $\mu$. If $(\lambda(x)-\mu(x))(1-F(x))$ is decreasing in $\mathrm{x}$, the crimping technology $\lambda$ produces higher profits than $\mu$.

While the hypotheses of Theorem 3 are not necessary for $\lambda$ to dominate $\mu$, it is necessary that $(\lambda(x)-\mu(x))(1-F(x))$ be decreasing for some values of $x$, just not all values.

Note that $\lambda(x)(1-F(x))$ is the revenue from selling only the crimped product to those with type greater than $x$. Recall that marginal revenue for the crimped good is

$$
M R_{L}=p-\frac{\left(1-F\left(\lambda^{-1}(p)\right)\right)}{f\left(\lambda^{-1}(p)\right)} \lambda^{\prime}\left(\lambda^{-1}(p)\right)=\lambda(x)-\frac{1-F(x)}{f(x)} \lambda^{\prime}(x)=-\frac{1}{f(x)} \frac{d}{d x} \lambda(x)(1-F(x)) .
$$

Thus, the hypothesis of Theorem 3 dictates that, if the marginal revenue of a $\lambda$ crimp lies above the marginal revenue of a $\mu$ crimp, the $\lambda$ crimp produces higher profits than the $\mu$ crimp. 


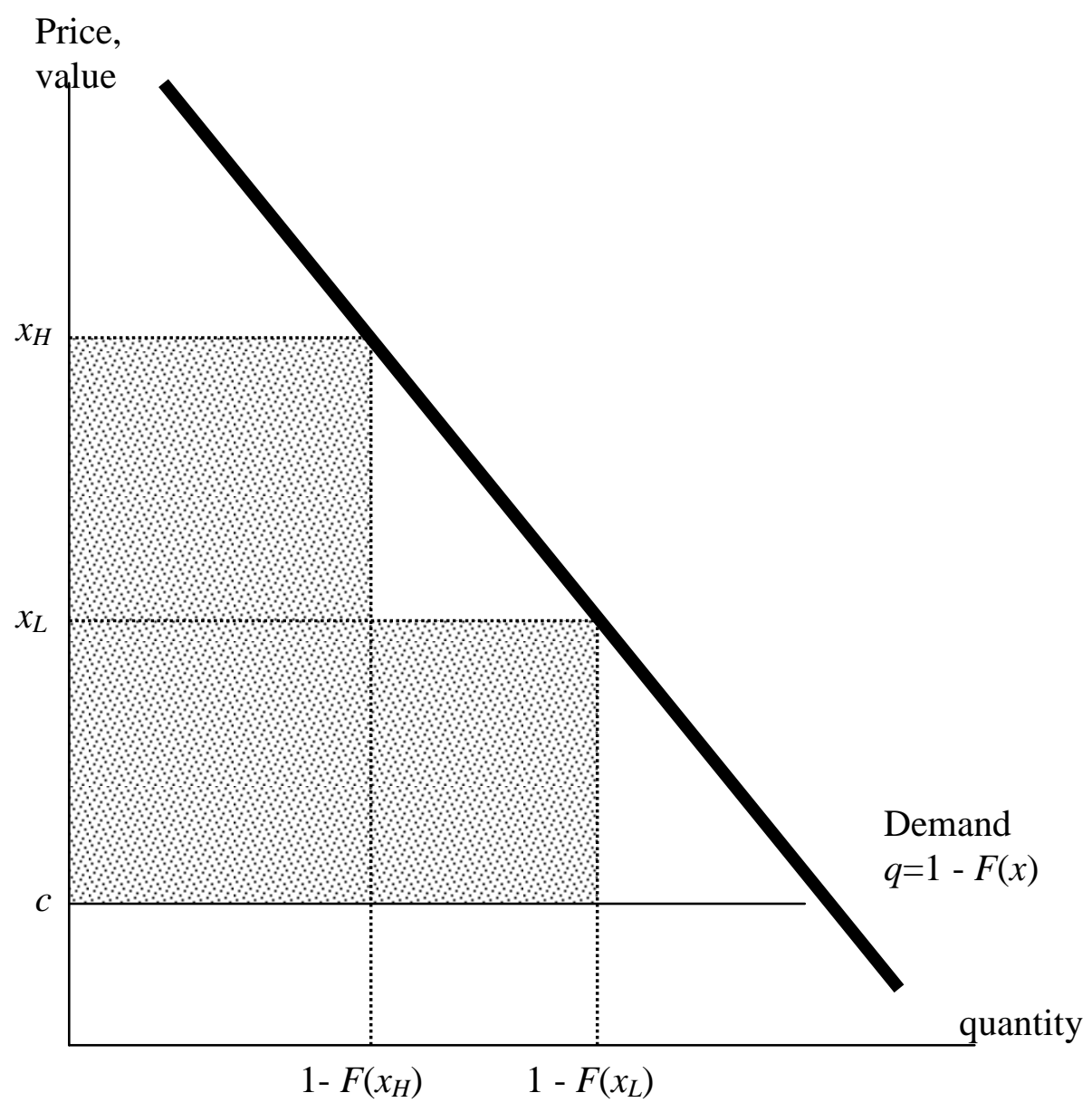

Figure 2: Perfect Two-Part Pricing

What is an ideal crimped product? The best crimp has the following properties (14) $\lambda\left(x_{H}\right)=\lambda\left(x_{L}\right)=x_{L}$

For fixed values of $x_{H}$ and $x_{L}$, this configuration maximizes the seller's profits. It is intuitive because it makes the crimp as bad as possible for high value customers, by forcing $\lambda\left(x_{H}\right)$ as low as it can go, but meanwhile maximizes the value of the crimped product to the low value customer. Such a crimped product yields profits of

$$
\pi=\left(1-F\left(x_{H}\right)\right) x_{H}+\left(F\left(x_{H}\right)-F\left(x_{L}\right)\right) x_{L}-c\left(1-F\left(x_{L}\right)\right) .
$$


This profit level is that achieved by perfect two-part pricing, which is illustrated in Figure 2. The effectiveness of a crimp is determined by (i) offering high value to the low value customer, and (ii) offering relatively low value to the high value customer. Thus, the ideal crimp is one that gives basic functionality with no high value services and it achieves the profitability that would arise when the customer types could be observed.

\section{Discussion}

Some crimps involve shutting off product features, as in versioning of software. When is it profitable to offer versions of the products with features shut off? According to Theorem 2, profitability of offering the crimped version hinges on $\frac{\lambda(v)-c}{v-c}$ being a decreasing function of $v$ around the monopoly price. Here, $v$ is the value of the joint version of the product and $\lambda$ the value of the crimped version. For example, if the value of the joint version is mostly realized for high type individuals, then it is profitable to offer the crimped version. If, in contrast, the synergies are approximately proportional to value, with high value customers being similar to low value customers but scaled up, then it will not be profitable to offer the crimped version.

Products sold with discount coupons, often offered on grocery items, can be viewed as a damaged product. In this view, the damaged product is the need to acquire a coupon in order to qualify for the discount. But what is the cost of the coupon? Suppose it takes $t$ units of time to sort through and find the relevant coupon, and a consumer of type $v$ values time at $w(v)$. Then the value of the good with coupon is $\lambda(v)=v-w(v) t$. Coupons are profitable to offer if $\frac{\lambda(v)-c}{v-c}=1-t \frac{w(v)}{v-c}$ is decreasing in $v$, or $\frac{w(v)}{v-c}$ is increasing, or $\frac{v-c}{w(v)}$ is decreasing, all evaluated at the monopoly price. 
This equivalency says that coupons are valuable if the gains from trade from a sale are a decreasing proportion of the wage, a type of good usually called a necessity, rather than a luxury. The theory suggests that coupons should be offered on necessities, but not on luxuries. In the U.S., coupons are often offered on family-oriented groceries, such as milk, paper towels, soft drinks and chips. Some of these products are not necessities in the usual sense of the term but probably have the property that willingness to pay as a proportion of income falls strongly as wages rise. 4

The ability to play a European disc has little value to a US customer who rarely travels, while it may have significant value to a wealthier US customer who travels frequently. Sharp's crimp of restricting the multi-region play of DVDs is likely an effective price discrimination tool, given the reasonable hypothesis that the high value customer travels more frequently than the low value customer.

The Saturday-night stayover requirement common for discount airfares in the United States imposes a substantial burden on most business travelers, who would like to be home on the weekend, and a relatively minor burden on most price-sensitive vacation travelers, who often are traveling either for an entire week or over the weekend. Consequently, the Saturday-night stayover conforms well to the optimal crimp.

Microsoft offers three main retail versions of its popular Office 2003 software, which contain up to seven products in a bundle. 5 All editions contain Word, Excel, Outlook and Powerpoint, which are writing, spreadsheet, calendar and email, and

\footnotetext{
${ }^{4}$ The consideration of economies of scale in coupon clipping reinforce the conclusion. Suppose, for instance, that collecting any coupons take a fixed amount of time $T$, and produce an average savings on the grocery bill of $Y$. Then $\lambda=v+Y-w(v) T$, which improves the chance that offering both products is profitable.

${ }^{5}$ I omit the Basic version, available only on a new PC, the Enterprise Professional version, available only through a volume license, and the Student and Teacher version, which is the Standard version for a price of $\$ 149$ to buyers in schools. There are other volume license products as well.
} 
presentation software, respectively. The two business-oriented versions include a contact manager add-in to Outlook, which helps manage and share a large number of customers, a program for producing more professional printed or web document like a brochure. The more expensive program adds Access, a database management tool.

\begin{tabular}{|l|l|l|l|l|l|l|l|l|}
\hline Table 2: Microsoft Office 2003 Retail Products (Source: Microsoft Website) \\
\hline & Word & Excel & Outlook & Powerpoint & $\begin{array}{l}\text { Business } \\
\text { Contact } \\
\text { Manager }\end{array}$ & Publisher & Access & Price \\
\hline Standard & $\bullet$ & $\bullet$ & $\bullet$ & $\bullet$ & & & & $\$ 399$ \\
\hline $\begin{array}{l}\text { Small } \\
\text { Business }\end{array}$ & $\bullet$ & $\bullet$ & $\bullet$ & $\bullet$ & $\bullet$ & $\bullet$ & & $\$ 449$ \\
\hline Professional & $\bullet$ & $\bullet$ & $\bullet$ & $\bullet$ & $\bullet$ & $\bullet$ & $\bullet$ & $\$ 499$ \\
\hline
\end{tabular}

A natural distinction is home and business users. Home users likely value Word and Outlook most highly, but make less use of Excel and Powerpoint. The home user would have little use for Business Contact Manager and Access, and leaving these products out of the standard edition is a sensible crimp. As home users may frequently engage in producing brochures and announcements for schools and the like, the omission of Publisher from the standard version is peculiar, although much of the functionality of Publisher is available in Word with substantial formatting effort. Similarly, the inclusion of Powerpoint and Excel are at least somewhat peculiar for the home user, since these are programs generally associated with business applications. The Office Basic version available on retail PCs excludes Powerpoint. Overall, the crimped version of office does not readily fit the framework predicted by the theory, unless a substantial home use is office work brought home. At best, the theory developed here is not very helpful understanding the versions of MS Office. It will be interesting to see if Microsoft's future product design better reflects the theory. 
The operating system Microsoft Windows XP comes in two main versions for a PC, Home and Professional, as well as Media, Tablet and 64 bit editions for specialized computers. The difference between the Home and Professional versions is that latter includes remote desktop, which lets another user take command of a PC remotely, automated system recovery, dynamic disk support, and other features that are primarily useful in a system with networked disks and corporate deployment. The main features of XP Professional that might have interested some home users are multi-processor support and fax software. These two main versions of Windows XP are well-designed in the sense that the features that have been omitted from the Home version are of little value to the relatively low value home user or small business, but of high value in enterprise applications, thus conforming well to the ideal crimp. It will prove interesting to evaluate the new program Windows Vista, which has eight distinct versions, in this light. 


\section{References}

Anderson, Eric and James Dana, "When is Price Discrimination Profitable?," unpublished, August 2005. Further information

Area 540, "Modification of the Sharp Remote Control,". http://www.area450.com/hardwaremods/remote-sharp.html

Armstrong, Mark and J ohn Vickers, "Competitive Price Discrimination," Rand J ournal of Economics, 32, no. 4, Winter 2001, 579-605.

Further information in IDEAS/RePEC

Armstrong, Mark, "Multiproduct Nonlinear Pricing", Econometrica, Vol. 64, No. 1. (J an., 1996), pp. 51-75. Further information in IDEAS/RePEC

Besanko, David, Shabtai Donnenfeld and Lawrence J . White, "The Multiproduct Firm, Quality Choice, and Regulation" The Journal of Industrial Economics, Vol. 36, No. 4. (J un., 1988), pp. 411-429. Further information in IDEAS/RePEC

Deneckere, Ray and R. Preston McAfee, "Damaged Goods," J ournal of Economics and Management Strategy 5, no. 2, Summer, 1996, 149-74.

Further information in IDEAS/RePEC

Ducker, Michael, “Hands on with the Treo 650,” TreoCentral, October 25, 2004. http://treocentral.com/content/Stories/474-1.htm.

Ellison, Glenn and Drew Fudenberg, "The Neo-Luddite's Lament: Excessive Upgrades in the Software Industry," The RAND J ournal of Economics, Vol. 31, No. 2. (Summer, 2000), pp. 253-272. Further information in IDEAS/RePEC

Hahn, J ong-Hee, “Damaged Durable Goods," Rand J ournal of Economics, 37, n0.1, Spring, 2006, 121-133. Further Information IDEAS/RePEC

Jing, Bing, "Network Externalities and Market Segmentation in a Monopoly," Economics Letters, 95, no. 1, April 2007, 7-13. Further Information IDEAS/RePEc

Johnson, Justin P., and David P Myatt, "Multiproduct Quality Competition: Fighting Brands and Product Line Pruning", American Economic Review, 93, n0. 3, 2003, 748774. Further information in IDEAS/RePEC

Johnson, Justin P., and David P Myatt, "Multiproduct Cournot Oligopoly", RAND J ournal of Economics, Autumn 2006. Further information

Kim, J ong Seok, "Optimal Price-Quality Schedules and Sustainability", The J ournal of Industrial Economics, Vol. 36, No. 2. (Dec., 1987), pp. 231-244.

Further information in IDEAS/RePEC 
Motta, Massimo, "Endogenous Quality Choice: Price vs. Quantity Competition”, The J ournal of Industrial Economics, Vol. 41, No. 2. (J un., 1993), pp. 113-131.

Further information in IDEAS/RePEC

Mussa, Michael and Sherwin Rosen, "Monopoly and Product Quality," Journal of Economic Theory 18, 301-317. Further information in IDEAS/RePEC

Srinagesh, Padmanabhan and Ralph M. Bradburd "Quality Distortion by a Discriminating Monopolist", The American Economic Review, Vol. 79, No. 1. (Mar., 1989), pp. 96-105. Further information in IDEAS/RePEC

Varian, Hal R., "Price Discrimination and Social Welfare", The American Economic

Review, Vol. 75, No. 4 (Sep., 1985), pp. 870-875. Further information in IDEAS/RePEC 


\section{Appendix: Proofs}

Proof of Lemma 1: Let I refer to the identify function. Then

$\mathrm{x}_{\mathrm{L}}=\lambda^{-1}\left(\mathrm{p}_{\mathrm{L}}\right)$, and

$\mathrm{x}_{\mathrm{H}}=(\mathrm{I}-\lambda)^{-1}\left(\mathrm{p}_{\mathrm{H}}-\mathrm{p}_{\mathrm{L}}\right)$

Thus, $\mathrm{x}_{\mathrm{L}}<\mathrm{x}_{\mathrm{H}}$

if and only if $\lambda^{-1}\left(\mathrm{p}_{\mathrm{L}}\right)<(\mathrm{I}-\lambda)^{-1}\left(\mathrm{p}_{\mathrm{H}}-\mathrm{p}_{\mathrm{L}}\right)$

if and only if $\lambda^{-1}\left(\mathrm{p}_{\mathrm{L}}\right)-\mathrm{p}_{\mathrm{L}}=(\mathrm{I}-\lambda)\left(\lambda^{-1}\left(\mathrm{p}_{\mathrm{L}}\right)\right)<\mathrm{p}_{\mathrm{H}}-\mathrm{p}_{\mathrm{L}}$

if and only if $\lambda^{-1}\left(\mathrm{p}_{\mathrm{L}}\right)<\mathrm{p}_{\mathrm{H}}$

if and only if $\mathrm{p}_{\mathrm{L}}<\lambda\left(\mathrm{p}_{\mathrm{H}}\right)$ as claimed

Proof of Theorem 1:

$$
\begin{aligned}
\frac{\partial \pi}{\partial x_{H}}= & -f\left(x_{H}\right)\left(x_{H}-\lambda\left(x_{H}\right)\right)+\left(1-F\left(x_{H}\right)\right)\left(1-\lambda^{\prime}\left(x_{H}\right)\right) \\
& =-f\left(x_{H}\right)\left(x_{H}-\lambda\left(x_{H}\right)-\frac{1-F\left(x_{H}\right)}{f\left(x_{H}\right)}\left(1-\lambda^{\prime}\left(x_{H}\right)\right)\right) \\
& =-f\left(x_{H}\right)\left(M R_{H}\left(x_{H}\right)-M_{L}\left(\lambda\left(x_{H}\right)\right)\right) \\
\frac{\partial \pi}{\partial x_{L}}= & -f\left(x_{L}\right)\left(\lambda\left(x_{L}\right)-c\right)+\left(1-F\left(x_{L}\right)\right) \lambda^{\prime}\left(x_{L}\right) \\
& =-f\left(x_{L}\right)\left(\lambda\left(x_{L}\right)-c+\frac{1-F\left(x_{L}\right)}{f\left(x_{L}\right)} \lambda^{\prime}\left(x_{L}\right)\right)=-f\left(x_{L}\right)\left(M_{L}\left(\lambda\left(x_{L}\right)\right)-c\right)
\end{aligned}
$$

Fix $\mathrm{x}_{\mathrm{L}}$ so that $\lambda\left(\mathrm{x}_{\mathrm{L}}\right)=\mathrm{c}$. By hypothesis, $\lambda(\mathrm{x})-\mathrm{c} \leq \lambda^{\prime}(\mathrm{x})(\mathrm{x}-\mathrm{c})$. For $\mathrm{x}_{\mathrm{H}} \geq \mathrm{x}_{\mathrm{L}}$,

$$
\begin{aligned}
x_{H}- & \lambda\left(x_{H}\right)-\frac{1-F\left(x_{H}\right)}{f\left(x_{H}\right)}\left(1-\lambda^{\prime}\left(x_{H}\right)\right) \\
& \geq \mathrm{C}+\frac{\lambda\left(x_{H}\right)-c}{\lambda^{\prime}\left(x_{H}\right)}-\lambda\left(x_{H}\right)-\frac{1-F\left(x_{H}\right)}{f\left(x_{H}\right)}\left(1-\lambda^{\prime}\left(x_{H}\right)\right)
\end{aligned}
$$




$$
\begin{aligned}
& =\frac{\lambda\left(\mathrm{x}_{\mathrm{H}}\right)-\mathrm{c}}{\lambda^{\prime}\left(\mathrm{x}_{\mathrm{H}}\right)}\left(1-\lambda^{\prime}\left(\mathrm{x}_{\mathrm{H}}\right)\right)-\frac{1-\mathrm{F}\left(\mathrm{x}_{\mathrm{H}}\right)}{\mathrm{f}\left(\mathrm{x}_{\mathrm{H}}\right)}\left(1-\lambda^{\prime}\left(\mathrm{x}_{\mathrm{H}}\right)\right) \\
& =\frac{1-\lambda^{\prime}\left(\mathrm{x}_{\mathrm{H}}\right)}{\lambda^{\prime}\left(\mathrm{x}_{\mathrm{H}}\right)}\left(\lambda\left(\mathrm{x}_{\mathrm{H}}\right)-\mathrm{c}-\lambda^{\prime}\left(\mathrm{x}_{\mathrm{H}}\right) \frac{1-\mathrm{F}\left(\mathrm{x}_{\mathrm{H}}\right)}{\mathrm{f}\left(\mathrm{x}_{\mathrm{H}}\right)}\right) \geq 0 .
\end{aligned}
$$

Thus, $\frac{\partial \pi}{\partial \mathrm{x}_{\mathrm{L}}}=0$ and $\mathrm{x}_{\mathrm{H}} \geq \mathrm{x}_{\mathrm{L}}$ implies $\frac{\partial \pi}{\partial \mathrm{x}_{\mathrm{H}}} \leq 0$, which implies that there is no non-trivial solution with both goods for sale.

Proof of Theorem 2: The monopoly price $\mathrm{p}^{\mathrm{H}}$ for the one good monopolist sets marginal revenue $\mathrm{MR}_{\mathrm{H}}$ equal to marginal cost, so

$$
p^{H}-\frac{1-F\left(p^{H}\right)}{f\left(p^{H}\right)}-c=0
$$

The effect on profits of a slight decrease in $\mathrm{x}_{\mathrm{L}}$ below $\mathrm{p}^{\mathrm{H}}$ is

$$
\begin{gathered}
\left.\frac{\partial \pi}{\partial x_{L}}\right|_{x_{L}=p^{H}}=-f\left(p^{H}\right)\left(\lambda\left(p^{H}\right)-c\right)+\left(1-F\left(p^{H}\right)\right) \lambda^{\prime}\left(p^{H}\right) \\
=-f\left(p^{H}\right)\left(\lambda\left(p^{H}\right)-c+\frac{1-F\left(p^{H}\right)}{f\left(p^{H}\right)} \lambda^{\prime}\left(p^{H}\right)\right) \\
=-f\left(p^{H}\right)\left(\lambda\left(p^{H}\right)-c+\left(p^{H}-c\right) \lambda^{\prime}\left(p^{H}\right)\right)<0 .
\end{gathered}
$$

Thus a slight decrease in $\mathrm{x}_{\mathrm{L}}$ increases profits, demonstrating the profitability of selling both qualities.

Proof of Theorem 3: Consider a crimp using the technology $\beta \lambda+(1-\beta) \mu$. Note that if it is optimal to offer a crimp for each of two technologies, it is optimal to offer one for the convex combination, by Theorem 2. If profits increase in $\beta$ as $\beta$ goes from 0 to $1, \lambda$ produces higher profits than $\mu$. From (5), these profits are

$$
\begin{array}{r}
\Pi(\beta)=\max _{\mathrm{x}_{\mathrm{H}} \geq \mathrm{x}_{\mathrm{L}}\left(1-\mathrm{F}\left(\mathrm{x}_{\mathrm{H}}\right)\right)\left(\mathrm{x}_{\mathrm{H}}-\left[\beta \lambda\left(\mathrm{x}_{\mathrm{H}}\right)+(1-\beta) \mu\left(\mathrm{x}_{\mathrm{H}}\right)\right]\right)}+\left(1-\mathrm{F}\left(\mathrm{x}_{\mathrm{L}}\right)\right)\left(\left[\beta \lambda\left(\mathrm{x}_{\mathrm{L}}\right)+(1-\beta) \mu\left(\mathrm{x}_{\mathrm{L}}\right)\right]-\mathrm{c}\right)
\end{array}
$$

Then, by the envelope theorem,

$\Pi^{\prime}(\beta)=-\left(1-F\left(x_{H}\right)\right)\left(\lambda\left(x_{H}\right)-\mu\left(x_{H}\right)\right)+\left(1-F\left(x_{L}\right)\right)\left(\lambda\left(x_{L}\right)-\mu\left(x_{L}\right)\right) \geq 0$ because $x_{L} \leq x_{H}$. 